\title{
Short communication: (What) To teach or not to teach - that is the question
}

Juan Carlos Santamarina PhD

Professor, King Abdullah University of Science and Technology, Thuwal,

Kingdom of Saudi Arabia (carlos.santamarina@kaust.edu.sa)

There has been an explosion of knowledge in geotechnical engineering, yet the art and science paradigm remains deeply rooted in the field. Geotechnical engineering students will face today's prevailing difficulties as well as new and demanding geotechnical challenges such as those associated with energy and the environment. Confronting these situations and needs requires a sound and resourceful foundation. Therefore, geotechnical engineering teachers must review their educational programmes (a) to reconsider the role of empiricism, (b) to prune incorrect concepts and biases (e.g., enduring misnomers, incorrect explanations, superseded graphical approaches, unsound tricks and fragile correlations, and education based on extremes (dry-saturated, clay-sand, drained-undrained)), and (c) to promote a careful understanding of fundamentals (e.g., the particulate nature of soils and fractured rocks, formation history, the essential relevance of effective stress, thermo-hydro-chemo-mechanical coupled processes, repetitive loads and ubiquitous localisations). Finally, they must continue reflecting on the role of the engineer in society, within an ever-changing world as the driver for innovation.

Note from the Author: An abridged version of this briefing appeared as an essay in the LinkedIn blog for Géotechnique Letters. Several colleagues participated in the discussion that followed; salient observations extracted directly from the blog are summarised in the Appendix at the end of this briefing. The thorough contribution by L. Wesley is reproduced in its entirety as a companion manuscript.

\section{Introduction}

The first century of modern geotechnology is coming to an end. There has been an explosion of knowledge in the field, and a great insight into soil and rock behaviour through exceptional experimental and numerical capabilities has been gained. Today, the field is broader than any single person can master, and geotechnical engineers publish in more journals than anyone can follow (probably more than 30 journals, complemented by a similar number of trade magazines). There is unlimited access to information, and effective measurement systems and powerful analysis/design tools are readily available.

The first century has also highlighted difficulties in geotechnical design, to the point that geotechnical engineers have extensively accepted that the field is a combination of both art and science. Could this be the reason for consistently disappointing blind prediction exercises? There is a need to reassess the role of empiricism, question often invisible biases and incorrect concepts or approaches that have crept into teaching and practice, and bring back an emphasis on deep understanding coupled with multidisciplinary fluency.
Research and education are warranted by difficulties and challenges in geotechnical engineering practice. Current students of the field will reach the prime of their professional careers at the time when geotechnical engineering challenges that are sprouting today will dominate their professional lives, for instance, issues related to climate change, sea level rise, energy needs and sustainability. Confronting those needs will require a sound and resourceful scientific foundation. In this context, geotechnical engineering teachers must pause to reflect on their educational programmes.

\section{Bare core: the fundamentals}

While knowledge has expanded, teaching time remains limited and only a very small subset of concepts can be covered in the curriculum. The author often wonders about the key fundamental concepts that students should deeply understand if academic programmes were forced to reduce the contents of the courses to a bare minimum - say, a few pages - while satisfying multidisciplinary fluency. The underlying assumption is that young engineers will be able readily to add pragmatic procedures to a well-funded knowledge structure while still preserving the engineering versatility fundamentals provide.

Clearly, young engineers will need mechanics (e.g., equilibrium and plasticity), physics (e.g., conservation), chemistry (e.g., water and minerals), biology (e.g., limiting factors to life and biomediated processes), earth science/geology (e.g., formation history) and materials science (e.g., particulate matter). 
For the sake of this briefing, the author will address the last of these. The course on soils starts with the fundamental realisation that soils are particulate materials. Then, all observations summarised in Table 1 are true and causally related. The particulate nature of soils is recognised in the early stages of soil mechanics, yet it is seldom emphasised in class. Observations in the table apply to all soils and fractured rocks.

\section{Not to teach (pruning)}

There are enduring misnomers, superseded practices and restraining recipes in the field. Those in the geotechnical engineering community all share responsibility for pruning these out; in particular, educators, journal editors and conference organisers can play an effective role to this end. The following are examples.

- Terms with multiple semantics. The term 'clay' is used to indicate size, mineral (crystal or amorphous), or any soil that plots above the A-line on the plasticity chart. Use the term 'clay' to indicate clay minerals, and classify fine-grained soils according to their sensitivity to changes in pore fluid chemistry.

- Misnomers. The salient example is 'cohesive soil' - this is a dangerous oxymoron indeed. Abandon the qualifier

\section{Soils are particulate geomaterials, therefore:}

Soils are inherently non-linear (Hertz and electrical contacts), non-elastic (Mindlin contact), porous and pervious (i.e., porosity between grains is interconnected).

Particle-level characteristics and processes integrate to make the macroscale response

- size: determines the balance between particle-level forces (capillary and electrical forces gain relevance when particles are smaller than $10-50 \mu \mathrm{m})$

- shape: reflects formation history and affects grain packing, anisotropy, stiffness, strength and permeability - among others

- spatial arrangement of grains: determined by electrical forces in fine-grained sediments (pore fluid pH and ionic concentration) and by grain shape and relative grain size in coarse-grained soils

- porosity: varies widely and is stress dependent in (unstructured) fine-grained soils, but varies in a narrow range and is mostly defined at the time of packing in coarse-grained soils.

The particulate skeleton (frictional) coexists with the pore fluids (viscous).

- Both are very different: the key is to anticipate their distinct responses to imposed boundary changes.

- The skeleton and the fluid interact: this gives rise to coupled fluid pressure, effective stress, volumetric strains and shear response.

- Mixed fluids add capillary effects onto the particulate skeleton.

- Generalisation: all hydro-chemo-bio-thermo-mechanical processes are coupled.

The mechanical behaviour of the particulate skeleton is effective stress dependent.

- This includes stiffness (Hertz), frictional strength (Coulomb), and dilation/contraction upon shear (Taylor).

- Frictional strength limits the maximum stress anisotropy a soil can experience.

- Other properties may depend on effective stress as well (e.g., thermal conductivity of dry soils).

Particle-level deformation mechanisms change with strain level.

- Small-strain deformation. It takes place at constant fabric and grain deformations concentrate at interparticle contacts; in this strain regime, volume change, pore pressure generation and frictional losses are minimal.

- Large-strain deformation. It involves fabric changes (the role of contact-level grain deformation vanishes).

- Threshold strain between the two regimes. It is higher for smaller particles and at higher confinement.

Soils are not inert and often change within the time scale of engineering projects.

- Corollary: natural soils may behave differently from freshly remoulded clay or recently packed sand. 
'cohesion', and related expressions such as 'cohesive soil' and 'cohesionless soil'.

- Incorrect concepts. The term 'lubrication' is often misused in discussions of friction and explanations of the dry branch of the compaction curve. Primary and secondary consolidations are imagined as sequential rather than concurrent processes. Peak strength and critical-state void ratio are inferred even when specimens have experienced progressive failure and shear localisation. Tensile strength is invoked to explain desiccation crack formation. And the term 'thixotropy' is indiscriminately used in relation to time-dependent changes in fine-grained sediments.

- Superseded. Still taught are graphical approaches that have become detached from their physical-mathematical underpinning (e.g., the determination of coefficient of consolidation using sqrt- $t$ or log- $t$ methods: a simple spreadsheet calculation can readily fit the diffusion equation to the data and incorporate other effects such as the change of permeability with void ratio). Teachers keep concepts developed for hand plotting and hand calculations (e.g., meaning of preconsolidation pressure and its determination), and preserve the use of parameters that add limited information (e.g., plastic limit (PL) is highly correlated to liquid limit for clay-dominant soils; then, we need to reassess its value and the adequacy of plasticity index-based correlations).

- Restrictive/simplistic tricks that are not sound. From 'buoyant unit weight' and unconsolidated-undrained tests to total stress analyses - paraphrasing J. Atkinson, are we not ready for a clean parting from total stress yet?

- Fragile correlations and equations with local validity. Diagnostic symptoms include dimensionally inhomogeneous expressions and equations that violate asymptotic trends for extreme values of the variable (e.g., the linear e- $\log \sigma^{\prime}$ equation). Instead, focus on physics-inspired correlations to attain more robust equations that satisfy asymptotic conditions.

\section{To tweak and refocus}

In an attempt to bring clarity, soil conditions have been polarised and a curriculum around extremes has been developed. Consider two cases. First, soils are taught as if they are either dry or water saturated, while reality involves these two extremes and all unsaturated conditions in between. Second, drained and undrained analyses are covered, yet these are two extremes when the rate of pore pressure dissipation is either much faster (drained) or much slower (undrained) than the rate of loading.

There are some old-sounding but most elegant concepts that the author likes to cover in class, but with renewed emphasis on understanding rather than on devoting full focus to the development of engineering solutions. Examples include 'feeling' equilibrium with Mohr circle, combining equilibrium and failure conditions in a Mohr-Coulomb analysis to show limiting stress anisotropy in soils, the elegance of elastic solutions, the 'essential engineering nature' of upper and lower bounds (i.e., what is needed is not the exact solution, but reliable and narrow bounds), and even flownets (i.e., to highlight the identification of boundary conditions and to 'experience' flow patterns and seepage forces).

\section{To teach (evolving emphasis)}

Gradually, the author's lectures are evolving by shifting emphasis and incorporating other topics that - in his mind - students will need in order to keep up to date and intellectually agile in a changing world.

- Place continued emphasis on the particulate nature of soils and fractured rocks, and the critical relevance of effective stress! Extend the coverage of other needed scientific foundations. (Note: early reviewers of this briefing suggested a dual track: one that emphasises skills that will be immediately useful in practice - with exposure to the scientific foundations - and another that emphasises the scientific foundations and provides less of the practice-oriented skills.)

- Present an updated discussion of formation history and diagenesis (with proper coverage of residual soils), bonding and structured soils (i.e., salient deviations from observations made in Table 1), natural and manufactured soils (e.g., mine tailings and fly ash), stratigraphy and spatial variability (at all scales).

- Increase emphasis on well-designed field tests to measure properties for engineering design. Principally, the laboratorymeasured stiffness/compressibility is critically affected by sampling effects and aggravated by seating effects; in particular, oedometer tests should be limited to situations where the anticipated vertical shortening is a significant fraction of the specimen initial height.

- Extend teaching examples to a wide range of fluids, pressure, effective stress and temperature conditions that upcoming geotechnical problems will impose (including grain-crushing effects).

Emphasise both short- and long-term performance monitoring with a focus on making predictions and assessing interpretations (noting that there are innate monitoring limitations such as accelerating bifurcations).

- Increase awareness of the pervasive tendency to localisations of all kinds which break down the common assumption of homogeneity (from shear bands and compaction bands to dissolution pipes, flow localisation, fingering and a wide range of opening mode discontinuities or fractures).

- Introduce repetitive loads (mechanical, thermal, chemical, moisture): they may determine long-term performance.

- Continue reflecting on the role of the engineer in society, within an ever-changing world as the driver for innovation.

\section{Closing}

Geotechnical engineering has evolved and continues to develop as a result of the synergistic interaction between education, research and practice. This synergism is needed today more than ever before as the field gains pre-eminent roles in the most challenging problems humanity has ever faced. Students should be encouraged to embrace these challenges so they thrive in the new opportunities that the field presents, and let this excitement permeate into the classroom. 
Geotechnical education has underplayed the importance of first principles while trying to focus on prescriptive solutions needed by practitioners to solve today's problems. If the pendulum is allowed to swing further toward the 'practice' end, advances needed to enhance the solution of today's problems will be delayed and future generations of students will be ill prepared to tackle the challenges that the profession will face.

Geotechnical engineering teachers are challenged to make difficult choices about their curriculum. Furthermore, they are constrained by the evolving civil engineering programmes that contain them. They should lead the change and define their role.

\section{Acknowledgements}

This briefing benefited from the writings, conversations, and feedback from many colleagues, in particular, E. Alonso, C. Arson, J. Atkinson, R. Bachus, R. Bonaparte, S. Chong, M. Dusseault, D. Frost, A. Garcia, A. Gens, G. Gudehus, J. Jang, P. Mayne, J. Mitchell, M. Pantazidou, S. Roshankhah, A. Schofield and R. Sullivan.

\section{Appendix: Compilation of responses posted on the blog}

Several colleagues participated in the discussion that followed the posting of this essay. The author takes the liberty of summarising salient observations by extracting them directly from their writings. The thorough contribution by L. Wesley is reproduced in its entirety as a companion manuscript.

Geotech: part of the broader civil engineering programme. A colleague reminded teachers that geotechnical engineering is part of the civil engineering programme; thus, it has to fit within the broader curriculum, and the development of skills, training and education. These provide constraints on what they can realistically cover. In this context, the geotechnical engineering course plays a critical role in training for solving problems, dealing with uncertainty, understanding the limitations of assumptions and the importance of experience.

How against what. While B. Anderson stated that teachers are focusing on the wrong material, especially in cases where only one geotechnical course is required for the degree, V. Diyaljee emphasised 'how to teach what to teach' and noted that many teachers lack field exposure and the experience of observation to appreciate the meaningfulness and correctness of results (discussed extensively in L. Wesley's contribution). On the same line, B. Jeffcoat-Sacco pointed out the value of 'actual work' when guided by great mentors and suggested that emphasis should be placed on 'how to think rather than what to think'. Similar observations were made by other colleagues; these concepts resurfaced in a subsequent insightful posting by E. Alonso in the same blog (LinkedIn group for Géotechnique Letters), who highlighted the central role of abstract thinking nourished by experience in creative problem solving.
'Cohesive soil'. J. Endicott reminded us that Professor Andrew Schofield has extensively spoken against the misuse of the term 'cohesion' in clays. (Note: I heard a similar argument for the first time from T. W. Lambe in 1983; eventually, it led to the essay 'Cohesive soil: a dangerous oxymoron', which circulated in the USA years later (Santamarina, 1997)). B. Kutter and U. Cilingir agreed that teaching cohesion as an intrinsic soil property is false and may lead to dangerous misconceptions. B. Kutter suggested that a better descriptor would be 'soils with measurable PL'.

Contraction-dilation transition is a clearer terminology than 'phase transformation' or 'characteristic state' (B. Kutter).

Critical-state soil mechanics (CSSM). Several replies reflected on the value of critical-state soil mechanics as a framework for the understanding of soil behaviour (U. Cilingir). Yet drawbacks in CSSM must be properly recognised - for example, modelling mixed soils (J. Endicott).

Experiments. A colleague prompted a discussion on the role of experiments and physical models to understand basic concepts, and to anchor often-misused numerical modelling onto the physical reality.

Models. V. Barvashov paraphrased British mathematician George Box who wrote, 'all models are wrong, but some are useful', to highlight the need for learning decision making in conditions of major scatter in sparse soil test data. J. Endicott suggested that specialisation requires a second degree and that a new graduate should not be expected to be able to undertake advanced modelling from day one.

Endless change. E. C. Leong reminded teachers that knowledge is always evolving; therefore, there is continuous tension between what is taught and what is required in practice. J. Endicott said that teaching should be fundamental and in line with currently accepted concepts and not out of date or over-elaborate. Finally, a colleague cautioned that in this time of readily available information, students often become engulfed in gathering information and fail to acquire knowledge.

\section{REFERENCE}

Santamarina JC (1997) 'Cohesive soil': a dangerous oxymoron. iGEM (The Internet Geotechnical Engineering Magazine). Georgia Institute of Technology, Atlanta, Georgia. See http:// www.ejge.com/iGEM/Oxymoron/Dangeoxi.htm (accessed 28/ 11/2015).

\section{WHAT DO YOU THINK?}

To discuss this paper, please submit up to 500 words to the editor at journals@ice.org.uk. Your contribution will be forwarded to the author(s) for a reply and, if considered appropriate by the editorial panel, will be published as a discussion in a future issue of the journal. 